\title{
The Mediating Role of Knowledge Creation Processes in the Relationship Between Social Media and Open Innovation
}

\author{
Ignacio Cepeda-Carrion ${ }^{1}$ - Jaime Ortega-Gutierrez ${ }^{1}$ - Aurora Garrido-Moreno ${ }^{2}$. \\ Juan-Gabriel Cegarra-Navarro ${ }^{3}$
}

Received: 17 May 2021 / Accepted: 19 January 2022

(c) The Author(s), under exclusive licence to Springer Science+Business Media, LLC, part of Springer Nature 2022

\begin{abstract}
The purpose of the study is to empirically examine the role of absorptive capacity, as a set of knowledge creation processes, in the relationship between social media and open innovation in the family firm context. In addition, the study analyses the impact of social media use as an antecedent of open innovation in the firms. The examined sample was composed by 113 responding family firms in Spain. The model was estimated through PLS-SEM with smartPLS software 3.3.3. Results confirm the key role played by absorptive capacity in the relationship between social media use and open innovation, proving also how social media use appears as a relevant enabler of open innovation practices. Moreover, findings support the importance of social media use for acquiring external information and knowledge which in turn can help family firms to gain more innovative opportunities. Our paper suggests that managers of family firms should foster an appropriate culture of learning in their firms and provide specific training to develop the staff ability to acquire, integrate and use information captured by digital platforms. Social media has totally transformed the way firms relate to the market and provides a useful tool to collect external knowledge and information. These tools are used by family firms as a new form to connect and collaborate with different stakeholders, so they have the potential to enhance open innovation activities. However, empirical research on the topic remains scarce and is challenging for managers to benefit from all the potential that social media can bring in fostering innovation and to develop dynamic capacities of knowledge management in the family firm context. This work sheds light on this topic.
\end{abstract}

This article is part of the Topical Collection on Enhancing the Adaptability of Family Businesses to the Knowledge-based Economy

Ignacio Cepeda-Carrion

icepeda@us.es

Extended author information available on the last page of the article

Published online: 10 February 2022 
Keywords Social media - Open innovation - Absorptive capacity $\cdot$ Family firms Knowledge management

\section{Introduction}

Family businesses are the most important in the economy of a country, and their significance becomes even greater if the consequences of their entrepreneurial work on the overall growth of a society are analysed (Basco, 2010). The defining characteristics of family businesses are focused on management engagement with congenital learning (Cegarra-Navarro \& Wensley, 2009) and on the passage of these businesses from one generation to another (Ruiz et al., 2010). As Brumana et al. (2017) point out, family firms adopt strategic behaviour conditioned by their idiosyncratic characteristics (e.g. family ownership, management, and involvement) and motivations (e.g. transgenerational succession). This, in turn, facilitates the emergence of a culture focused on keeping the future in mind and reinforcing constancy (Moss et al., 2014).

Open innovation has become one of the most relevant concepts in innovation management, and it basically involves opening the innovation process to collaborate with external agents or outsiders (Huizingh, 2011). Open innovation may be considered to be particularly troubling in family businesses where their managers are often constrained by a lack of resources and information (Popa et al., 2017; Jalilvand et al., 2019). Since open social media use (SM) can provide an opportunity to foster workplace collaboration of family businesses staff with external stakeholders (Aral et al., 2013; De Zubielqui et al., 2019), social media use can be seen as a source of external information (Mention, 2011; Mention et al., 2019) and a facilitator of open innovation (Mount \& García, 2014).

Previous studies have examined the impact of social media in knowledge creation and innovation processes (Papa et al., 2018; Pérez-González et al., 2017), its impact in fostering incremental and radical innovations (Torres de Oliveira et al., 2019). Following an open innovation perspective, De Zubielqui et al. (2019) empirically observed that external knowledge flows from market-based actors sourced by social media enhanced innovation, and they noted that it was necessary to better examine specific organisational mechanisms facilitating effective knowledge transfer in this process (Keegan \& Rowley, 2017).

It is worth noting that information is not the same as knowledge. Although the information provided by the social media use is valuable, it may be more appropriate to assimilate it and apply it to commercial ends (Cohen \& Levinthal, 1990). In doing so, absorptive capacity has been recognized as a relevant prerequisite to develop open innovation activities (Huizingh, 2011; Ooms et al., 2015a, b; Spithoven et al., 2010). Absorptive capacity involves a set of organizational routines and processes through which firms acquire, assimilate, transform, and exploit knowledge in order to create value and obtain a competitive advantage (Zahra \& George, 2002).

Even though social media use has been considered as a key tool to facilitate open innovation, empirical research on the combined effect of social media use and absorptive capacity on enhancing open innovation has not been properly examined 
in the literature (Torres de Oliveira et al., 2019). These complex relationships raise a number of important KM-related questions. How does social media use enhance open innovation practices and absorptive capacity in family firms? Is there a mediating effect of absorptive capacity of the impact of social media use on open innovation? With the introduction of "social media use" and a subsequent measurement instrument, this study makes three significant contributions to the field of knowledge management in family firm context.

First, this study conceptualizes social media use (SM) and distinguishes the construct from social media presence. A conceptual delineation is vital as it captures the essential characteristics of the construct, its observable manifestations and the interrelationships (Tajvidi \& Karami, 2021). Second, by developing a measurement instrument to quantify the SM of Spanish family firms, this study addresses an important empirical challenge of family firms, which is the contribution of social networking to non-financial performances, such as open innovation and absorptive capacity (Chukwujioke Agbimi, 2019). Finally, testing both, the direct and indirect effects of SM on open innovation, this study reveals promising research opportunities by proposing absorptive capacity as a mediator between SM and open innovation. Therefore, the model offers future researchers a wide range of research avenues to uncover the black box of SM in family firms (Strike et al., 2018).

\section{Research Model and Hypotheses}

\section{Social Media and Open Innovation}

In recent years, scholarly attention has been focused on better understanding the role of social media in creating and managing knowledge flows both within the firm and across organizational boundaries, which can transform in new ideas for product and service development (Bhimani et al., 2019). There is a growing interest, both in the business and in the academic world, in examining how social media use can enhance open innovation activities in the family firms.

Social media can been defined as "a group of Internet-based applications that build on the ideological and technological foundations of Web 2.0, and that allow the creation and exchange of user generated content" (Kaplan \& Haenlin, 2010, p. 61). It encompasses a set of internet-based digital technologies, like blogs, microblogging platforms (e.g. Twitter), social networking sites (Facebook), video and photo sharing sites (Youtube, Instagram) instant messaging tools (Whatsapp), online product review sites (Tripadvisor) or forums, which allow their users to create personal profiles and exchange content (Patroni et al., 2021). In terms of users, at a global level, Facebook has the leadership in numbers of users, having reached currently the figure of 2.85 billion monthly active users, followed by Youtube (2.29 billions) and Whatsapp (2 billion) (Statista, 2021).

Considering that customers frequently use social media platforms to verbalize their opinions about products and services, an increasing number of organizations are trying to engage customers and tap into customer conversations in these platforms for innovation purposes (Patroni et al., 2021). In this vein, we can 
find particular examples of specific social media platforms developed by firms in order to capture useful knowledge to support open innovation. It is particularly known the case of Starbucks, which in 2008 created the platform "MyStarbucksIdea", to engage customers to participate offering new ideas for new products. Customers were considered as both creators and evaluators of ideas, and the launching of the platform was a success, receiving thousands of novel ideas for new product development (Chua \& Banerjee, 2013). Other illustrative example of a company that has developed its own social media platform to leverage open innovation is Lego, the Danish toy manufacturer (Rass et al., 2013). To this end, the launched "LEGO Ideas" allows users to post and share their ideas and also vote other users' proposals. This site has become one of the most successful online innovation platforms, attracting more than one million registered users since its launching in 2014, which have contributed to the creation of over thirty thousand original block models (Qi et al., 2021).

Additionally, firms are also using public social media platforms, not purposefully created for innovation purposes, in order to leverage customer conversations and capture customer knowledge. In this sense, Patroni et al. (2021) examined the use of Facebook to relate with customers by one of the world's largest retailers and observed how the capability to engage customer via this platform can provide innovation-relevant information, acting as external enabler of the holistic innovation process.

As we have explained before, the use of social media tools offers business an emerging opportunity to source new ideas and co-create those ideas with customers, so it has a great potential to improve organizational innovation processes and outcomes (Casprini et al., 2017; Torres de Oliveira et al., 2019). Drawing on the dynamic capabilities theory, those authors confirmed that the use of social media tools enables the development of sensing and seizing capabilities. By using these platforms, firms can first identify emerging opportunities related with customers' needs (Sashi, 2012) and seize co-creation processes to produce specific innovations (Parveen et al., 2016). Moreover, in the context of open innovation, the application of social media for exploration and exploitation activities specifically enhances creativity, expertise, and collective intelligence, supporting firm ambidexterity during new product ideation (Mount \& Garcia, 2014).

It has been recognized that in current hyper-competitive environments, social media platforms enable faster information flow and better knowledge sharing across their internal and external stakeholders, allowing firms to capture valuable ideas to become more innovative (Lam et al., 2016). Particularly, social media tools are being used to facilitate diverse activities in the innovation process: information and knowledge sharing in idea generation and new product development, employee collaboration and internal communication, inter-firm cooperation and supply chain management (De Zubielqui et al., 2019; Lam et al., 2016).

It is well documented how firms from different sectors are using these tools to generate new ideas and enhance co-creation with customers. A well-known example is the case of Inditex Group. Inditex is the largest and most important Spanish family business and one of the most important at a global level. 
Specifically with its main brand, Zara, it has been developing and investing heavily in online platforms for years and has a global e-commerce platform in operation, integrating all the markets, countries and social networks in which it is present and through which it interacts with its customers and allowing customers to provide direct feedback on current offerings and submit new ideas for product or service development (Gallaugher \& Ransbotham, 2010). Many of the family businesses due to the pandemic have had to boost their digital path in order to adapt to the big changes and follow the path of big companies like Inditex.

Different studies in the literature have confirmed a positive effect of social media use on enhancing firm innovation activities (Chukwujioke Agbimi, 2019; Patroni et al., 2021; Rass et al., 2013; Torres de Oliveira et al., 2019). García-Morales et al. (2018) observed how social media use enhanced knowledge competences and innovation capabilities, translating also into improved business performance. Similarly, Palacios-Marques et al. (2015) focusing on data from the hotel sector confirmed a statistically significant positive relationship between online social networks and innovation capacity in the examined firms. Moreover, De Zubielqui et al. (2019), using a large-scale survey of SMEs from different sectors, observed a significant positive relationship between knowledge sourced via social media from marketbased actors and innovativeness. Based in all the above, we propose that:

H1. Social Media use positively affects Open Innovation activities.

\section{Social Media and Absorptive Capacity}

Within the knowledge management, absorptive capacity is one of the most important research constructs which have emerged in recent decades, and it has been particularly used in information systems literature. It refers to the firm's ability to identify, assimilate and exploit knowledge from the environment, through a continual learning process (Lane et al., 2006). As Zahra and George (2002) highlighted, absorptive capacity can be considered as a key dynamic capability that enables the creation of other organizational competences and can provide the firm with multiple sources of competitive advantage in high-changing environments. We followed Zahra and George (2002)'s conceptualization and assume that absorptive capacity is composed by two subsets and four dimensions. These subsets are potential absorptive capacity which involves the acquisition and assimilation of knowledge and realized absorptive capacity, which comprises the firm's capacity to transform and exploit assimilated knowledge by incorporating it into the firm's operations. These four dimensions enable firms to reconfigure its resource base and be able to adapt it to changing markets conditions to achieve thus a competitive advantage (Spithoven et al., 2010).

In current turbulent markets, family firms need to make use of internal and external information movements, to be able to build knowledge-based advantage over their competitors (Lam et al., 2016). Prior studies suggest that firms' exposure to external knowledge sources can be considered an effective antecedent of absorptive capacity, and the diversity of these sources can significantly enhance their acquisition and assimilation capabilities (Moilanen et al., 2014; Zahra \& George, 2002). 
In this context, the use of social media tools appears as a valuable means to foster knowledge exchange both inside and across family firm boundaries, enhancing also organizational learning. These platforms facilitate family firm's interactions with their stakeholders (customers, suppliers, partners), as they have become a suitable environment to share information, collaborate and build relationships (PalaciosMarques et al., 2015). Consequently, social media use is going to play a key role in building absorptive capacities in firms (Ooms et al., 2015a, b).

In this vein, Schlagwein and $\mathrm{Hu}$ (2017) conducted an extensive analysis of the social media literature and conclude that the use of these platforms effectively increases an organization's absorptive capacity. First, social media use supports the family business' ability for exploratory learning (understanding and acquiring external knowledge), as it allows to take up market information and patrol user-generated content more quickly and effectively. Second, social media also enhances transformative learning (interpreting and assimilating knowledge) because it fosters crowdsourcing processes and can help to leverage collective intelligence for the organization. And finally, these authors indicate that social media may also support the family firm's ability for exploitative learning, allowing new business applications or business processes to be created more effectively.

In this vein, it has been stated in prior literature that social media use enhances absorptive capacity in family firms. Scuotto et al. (2017), examining a sample of knowledge-intensive and labour-intensive SMEs, confirmed that the use of social networking platforms exerted a positive influence on the absorptive capacity of those family businesses. Moreover, Ooms et al. (2015a, b) also explored the topic in a qualitative way, through explorative case studies conducted in high-tech companies. Their results note that social media can be considered boundary-spanning tools and show how their use adds transparent and multidirectional interactions that can help to build and maintain absorptive capacity. Thus, based on prior evidence, the following hypothesis is proposed:

H2. Social Media use positively affects Absorptive Capacity.

\section{Absorptive Capacity and Open Innovation}

Absorptive capacity has been widely recognized in the literature as a key precondition for open innovation success (Naqshbandi \& Tabche, 2018; Rangus et al., 2017; Spithoven et al., 2010), in fact, open innovation is a great tool for the family business to face the market (Baron, 2021).

To survive in current turbulent environments, family firms need to implement diverse knowledge-enhancing practices to enhance their ability to quickly create new products and services (Ali \& Park, 2016; Chaudhary \& Batra, 2018). As we previously explained, absorptive capacity stimulates the acquisition, assimilation, transformation and exploitation of external knowledge, and also enables the establishing of valuable synergies with internal generated knowledge in the family firm (Chaudhary \& Batra, 2018). Both ways of acquiring knowledge are complementary and are going to effectively support innovation activities (Garcia-Morales et al., 
2007). Likewise, Moilanen et al. (2014) sustain that absorptive capacity not only acts as a tool for processing external knowledge, it is also considered as a conduit for transferring knowledge within the family firm, so it is going to play a key role in facilitating innovation (Sirmon \& Hitt, 2003).

Research results show a close relationship between absorptive capacity and open innovation not only in manufacturing and high-tech firms, but also in a service context (Garcia-Morales et al., 2007). In fact, absorptive capacity has been conceptualized as a dynamic capability that allows a family firm to transform knowledge into new products, services or processes to support innovation (Ali \& Park, 2016; Cepeda-Carrion et al., 2012; Chaudhary \& Batra, 2018). Consequently, from the own definition of the concept, we can derive its key role in enabling firms' innovativeness. (Sirmon \& Hitt, 2003).

As we explained before, absorptive capacity has been frequently recognized as a crucial source of innovation success (Cepeda-Carrion et al., 2012), and several studies have empirically examined the phenomenon. Moilanen et al. (2014), drawing on an extensive sample of SMEs, from manufacturing and service sectors, confirmed how absorptive capacity relates positively to innovation performance in all the firms of the sample. Scuotto et al. (2017) also confirm empirically this positive relationship and concluded that absorptive capacity enable firms to acquire, assimilate and transfer external knowledge, helping firms to generate new ideas and enhancing their innovativeness. Additionally, Ali and Park (2016) developed a disaggregated analysis of the issue, building on a sample of manufacturing firms, from different subsectors and sizes. They operationalize the two dimensions of absorptive capacity (potential versus realized absorptive capacity) separately and examined the specific impact of both variables on organizational innovation. Results confirm that potential and realized absorptive capacity works sequentially and directly influenced open innovation in family firms (which included product, process and management innovation). Consequently, we assume that absorptive capacity will play a key role in fostering innovation activities, and we formulate the following hypothesis:

H3. Absorptive capacity positively affects open innovation.

\section{The Mediating Role of Absorptive Capacity}

By accessing external information sources, organizations gain more opportunities to obtain valuable knowledge and integrate it into their innovation processes (De Zubielqui et al., 2019). As we previously explained, the use of social media tools provides companies with enormous potential and possibilities for initiating open innovations (Torres de Oliveira et al., 2019). However, not all the external information that companies have access is necessary, timely or appropriate (CegarraSánchez et al., 2018; Sánchez-Casado et al., 2015). In fact, special attention is required because social media can amplify the negative effects of misunderstandings, created via gossip, lies or fake news (Thompson, 2008). In order to address this 
issue, we suggest that absorptive capacity will mediate the relationship between the use of social media and open innovation, as we explain below.

Since the open innovation paradigm relies on capturing knowledge from external relationships, an appropriate internal environment is thus a must before building relationships with external partners (Naqshbandi \& Tabche, 2018). It should be noted here that one thing is to have access to external information, quite another is to learn and create knowledge to innovate and seize opportunities (Martinez et al., 2014; Ooms et al., 2015a, b). By using social media tools, family firms have access to large amounts of information from different sources, but this information needs to be processed, integrated and shared to transform it into valuable knowledge, which transforms into innovative ideas. Consequently, without an appropriate absorptive capacity, external knowledge has little value for the firm (Moilanen et al., 2014).

It is clear that open-innovation involves acquiring external information to foster organizations' outcomes (Hoy \& Sharma, 2010; Miller \& Le Breton-Miller, 2005; West et al., 2014). However, despite the predominant role of social media in sharing information, the relationship between these two dimensions has not been researched adequately (Ngai et al., 2015). For example, the alternative of considering absorptive capability like a moderator would mean that for the better but sometimes for the worse, all the external information provided by the social media may be used for innovations (i.e. the moderator effect of absorptive capacity accelerates and decelerates this process). However, the partial mediation model shown in Fig. 1 points to absorptive capability as a mechanism for acquiring, assimilating, transforming and exploiting the information provided by social media by setting standard operating procedures, structural artefacts and mental models which can lead both mitigation of unverified information and application of new knowledge. Therefore, in line with previous studies, this research highlights the importance to encourage managers of family firms to support absorptive capability for obtaining, contrasting, filtering and updating information provided by social media (Ooms et al., 2015a, b).

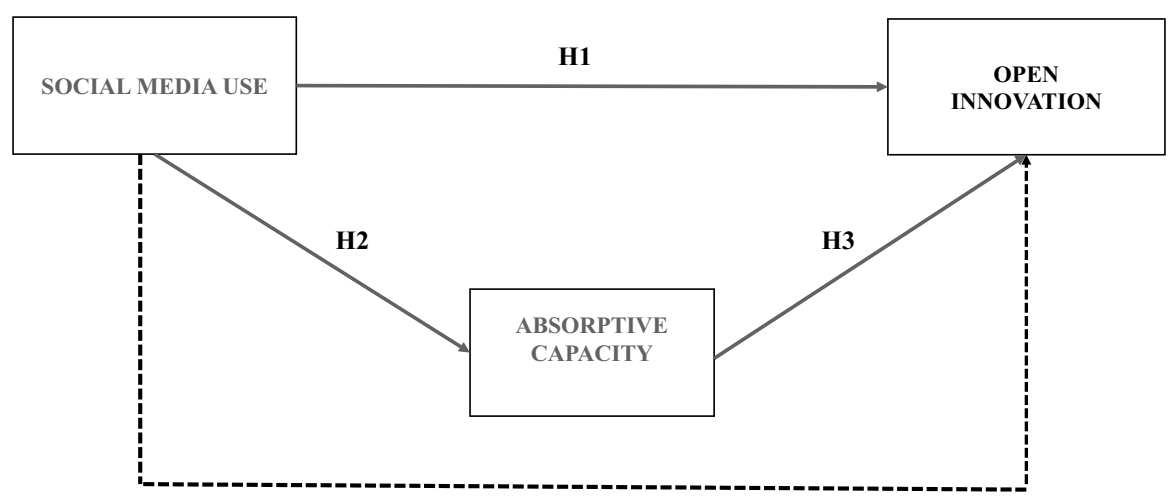

H4: Mediating effect

Fig. 1 Proposed research model 
Literature has demonstrated that absorptive capacity may be useful to channel external information by improving its transformation into knowledge and enhancing the innovation potential of the company (Chun-Yao, 2011; Cohen \& Levinthal, 2006; Escribano et al., 2009). In this vein, Scuotto et al. (2017) empirically observed that the process of creating new knowledge to promote innovation cannot be efficient without the use of social media and a solid absorptive capacity. Hence, drawing on a sample of SMEs, they confirmed that higher levels of absorptive capacity through the use of social networking sites positively influenced innovation performance. Additionally, Moilanen et al. (2014) also found that the absorptive capacity of a firm mediates the relationship between external knowledge inflows and innovation outcomes. Their findings suggest that to benefit from external knowledge flows, it is crucial that the family firm possesses the capability of identifying and evaluating the potential value of this external knowledge. Therefore, we suggest that:

H4. Absorptive capacity mediates the relationship social media use and open innovation.

Figure 1 presents the proposed research model, including the hypothesized relationships between social media use, absorptive capacity and open innovation.

\section{Research Methodology}

\section{Sample and Data}

The firms selected for this study were Spanish family firms in the services sector located in Spain, with more than 10 employees and 5 years of age. These criteria were introduced to ensure that companies had a certain level of complexity which would require a high use of technological tools and the development of open innovation activities.

Additionally, we considered that the Spanish family firms provide an appropriate context to empirically test the research hypotheses.

In addition to its economic relevance, the service sector is specifically appropriate to perform our study because service activities are the result of a co-production and interactivity, to attempt to achieve a superior value and experience, and they involve a high level of contact between customers and service providers (Mention, 2011).

Moreover, the family business and the relation with the innovation have become objects of growing attention for management researchers and managers (Block, 2009; Hoy \& Sharma, 2010; Miller \& Le Breton-Miller, 2005; Sharma et al., 2012).

The unique characteristics of family firms can affect the way in which they develop innovation activities (De Massis et al., 2013; Sirmon \& Hitt, 2003).

In addition, studies in different countries have demonstrated the important role played by family businesses in relation to economic growth and impact on the gross domestic product (GPD) of each country, as well as in the generation of employment (Barroso-Martinez et al., 2013; Pistrui et al., 2001; Anderson \& Reeb, 2003). 
This study addresses an important empirical challenge of family firms, which is the contribution of social networking to non-financial performances, such as open innovation and absorptive capacity (Chukwujioke Agbimi, 2019). Moreover, this study reveals promising research opportunities by proposing absorptive capacity as a mediator between SM and open innovation in family firms. Therefore, the model offers future researchers in family firm context a wide range of research avenues to uncover the black box of SM in family firms (Strike et al., 2018).

The firms' contact data was extracted from the database SABI that is a database of 2.5 million Spanish companies. As a result, 338 family firms with more than 10 employees and 5 years of age were identified and selected. In total, 338 managers of family firms of services sector receive telephone and mailing invitations to participate in this study. The process yields a total of 113 valid questionnaires $(33.43 \%$ response rate). A post analysis of power statistics on this sample reveals that estimations are not conditioned by the sample size. Table 1 shows the characteristics of the sample.

\section{Measures}

Figure 1 shows the proposed research model of the study. This work uses and adapts scales from previous studies in which the items and responses appear on a sevenpoint Likert scale ranging from 1: I completely disagree to 7: I completely agree.

In order to measures social media use (SM), the study adopts the one-dimensional scale of Tajvidi and Karami (2017), which had been tested in service firms in prior studies. In this scale, we had asked the firms about the level of use of several social networks. This scale presents 7 items. The study adopts a composite form for the all constructs in our model. Social media use (SM) was estimated as mode B composite and as mode $\mathrm{A}$ for the rest of the two constructs (i.e. open innovation (OI) and absorptive capacity (AC)). The reason for adopting a structure of composite for our model's construct is that all of them have been considered as human design tools to

Table 1 Sample characteristics

\begin{tabular}{ll}
\hline Size/age & Number of firms \\
\hline Size (employees) & \\
$10-50$ & 58 \\
$51-100$ & 29 \\
$101-200$ & 13 \\
$201-500$ & 10 \\
+500 & 3 \\
Age (years) & \\
$5-10$ & 7 \\
$11-25$ & 26 \\
$26-50$ & 66 \\
+50 & 14 \\
Total sample & 113 \\
\hline
\end{tabular}


measure or operationalize latent variable that is not easily measured in the nature (Henseler, 2017).

The SMU indicators modelled as mode B composites imply that they do not necessarily correlate; consequently, traditional reliability and validity assessments are inappropriate and illogical for a mode B composite (Bollen, 1989; Hair et al., 2019).

To measure the open innovation, in the current work, we have adopted the scale of Oltra et al. (2018). In this scale, we had asked the managers of our sample about the innovation practices adopted in their companies in the last 3 years. This scale presents 8 items. Finally, to assess the absorptive capacity, in this study, we adopt the multidimensional scale of Jansen et al. (2005). This scale is based in the prior studies of Zahra and George (2002), and the absorptive capacity is composed by PACAP (potential absorptive capacity) and RACAP (realised absorptive capacity). This scale is a multidimensional scale of 4 dimensions, two dimensions of PACAP: acquisition (AC) and assimilation (AS) of new external knowledge and two dimensions of RACAP: the transformation (KT) and exploitation (KE) of new external knowledge.

\section{Data Analysis}

In our model as we said, all measures are operationalized as composites (Henseler, 2017; Rigdon, 2016); therefore, we decide using PLS-SEM to test our model and the hypotheses. The reasons about this are the following: (1) we used composites estimated in mode A and mode B (Hair et al., 2016; Rigdon et al., 2017); (2) we adopted an explanatory approach following Henseler (2017). The composites are estimated in mode A when the indicators that compound the latent variable are correlated. A two-step process has been pointed out to assess models in an explanatory way with PLS-SEM, (Hair et al., 2019): (1) assessment of measurement model and (2) assessment of structural model.

We used a bootstrap procedure (Chin, 1998) in order to find significance of indices. With this bootstrapping, that is a resampling procedure, we are able to determine the significance of path coefficients and weights and loadings of indicators for each composites (i.e. latent variable). We use for data analysis the software package SmartPLS 3.2.6. (Ringle et al., 2015), and for mediation, we follow the procedure described by Nitzl et al. (2016) and Cepeda-Carrión et al. (2017).

A good measurement model should demonstrate sufficient reliability and validity. According to Henseler et al. (2015), $\rho$ A, Jöreskog's rho and Cronbach's alpha are the most suitable measures of the consistency reliability. Reliability values greater than 0.7 indicate appropiate reliability in the prior phases of research and values as high as 0.8 or 0.9 would be used in more advanced phases of the research (Nunnally, 1978), which are higher than the most usual values. As Fornell and Larcker (1981) argues, the score of average variance extracted (AVE) is a measure of unidimensionality. Finally, Fornell and Larcker's criterion provides evidence of discriminant validity of reflective constructs (i.e. Mode A composite) (Hair et al., 2014).

The path is a very important indicator in the structural model, and it is considered the most important result. Bootstrap percentile confidence intervals help in the 
Table 2 Indicators loadings of mode A composites

\begin{tabular}{lll}
\hline Constructs & AC & OI \\
\hline AC & 0.912 & \\
AS & 0.910 & \\
KE & 0.938 & \\
KT & 0.930 & \\
OI1 & & 0.848 \\
OI2 & & 0.853 \\
OI3 & & 0.781 \\
OI6 & & 0.762 \\
Mean & 5.99 & 6.13 \\
SD & 1.17 & 1.01 \\
CA & 0.942 & 0.827 \\
rho_A & 0.943 & 0.833 \\
CR & 0.958 & 0.885 \\
AVE & 0.851 & 0.659 \\
\hline
\end{tabular}

Mean the average score for all of the items included in this measure, S.D. standard deviation, $C A$ Cronbach's alpha, $C R$ composite reliability, $A V E$ average variance extracted

generalisation from sample to population (Cohen, 1988; Aguirre-Urreta \& Ronkko, 2018).

\section{Results}

\section{Measurement Model}

On the measurement model, the results indicate that all the requirements usually established are checked. First, because all the value of standardized loadings (mode A composites) are greater than 0.7 (Table 2); therefore, the individual items are reliable. Second, all the consistent measures of model are greater than 0.8 (Table 2); this model meets the prerequisite of construct reliability. Additionally, the value of AVE (average variance extracted) exceeds the limit of 0.5 (Table 2) for composite

Table 3 Indicators weights and significance of mode B composite

\begin{tabular}{lrll}
\hline Social media use & Weights & $t$-value & $p$-value \\
\hline SM1 & 0.305 & 1.783 & 0.075 \\
SM2 & 0.247 & 1.658 & 0.097 \\
SM3 & -0.065 & 0.642 & 0.521 \\
SM4 & 0.145 & 1.813 & 0.070 \\
SM5 & -0.148 & 2.044 & 0.041 \\
SM6 & 0.443 & 4.079 & 0.000 \\
SM7 & -0.169 & 2.338 & 0.019 \\
\hline
\end{tabular}

The significance of the weights was carried out through a two-tail's bootstrap procedure of 5000 subsamples 
Table 4 Fornell-Larcker's criteria

\begin{tabular}{llll}
\hline Constructs & AC & OI & SM \\
\hline AC & 0.923 & & \\
OI & 0.787 & 0.812 & \\
SM & 0.756 & 0.840 & n.a \\
\hline
\end{tabular}

Diagonal entries are the square root of the average variance extracted. Off-diagonal elements are correlations among constructs

unidimensionality, and these latent variables therefore achieve convergent validity. Table 3 shows the weights and significance of mode B composite's indicators (social media use). Finally, all mode A composites attain discriminant validity, as the table of Fornell and Larcker criterion indicates (Table 4).

\section{Structural Model}

The use of bootstrapping (5000 resamples) generates standard errors and the value of $t$-statistics serve to assess the statistical significance of the path coefficients (Henseler et al., 2009). The percentile bootstraps at the $95 \%$ confidence interval are presented in Table 4, where it is possible that all the direct and indirect effects are supported. Figure 2 presents the final estimated model.

The results show that the social media use is an antecedent of open innovation (H1) and absorptive capacity (H2), and therefore, the family firms that usually use social media to connect with their customer and stakeholders probably are more oriented to develop open innovation practices and absorption capacity tasks. The results also show that when a family firm makes absorption capacity tasks, they probably could develop open innovation practices (H3) and to reach better performance. These results confirm the proposed direct relationships, and the H1, H2 and $\mathrm{H} 3$ are supported according to prior studies.

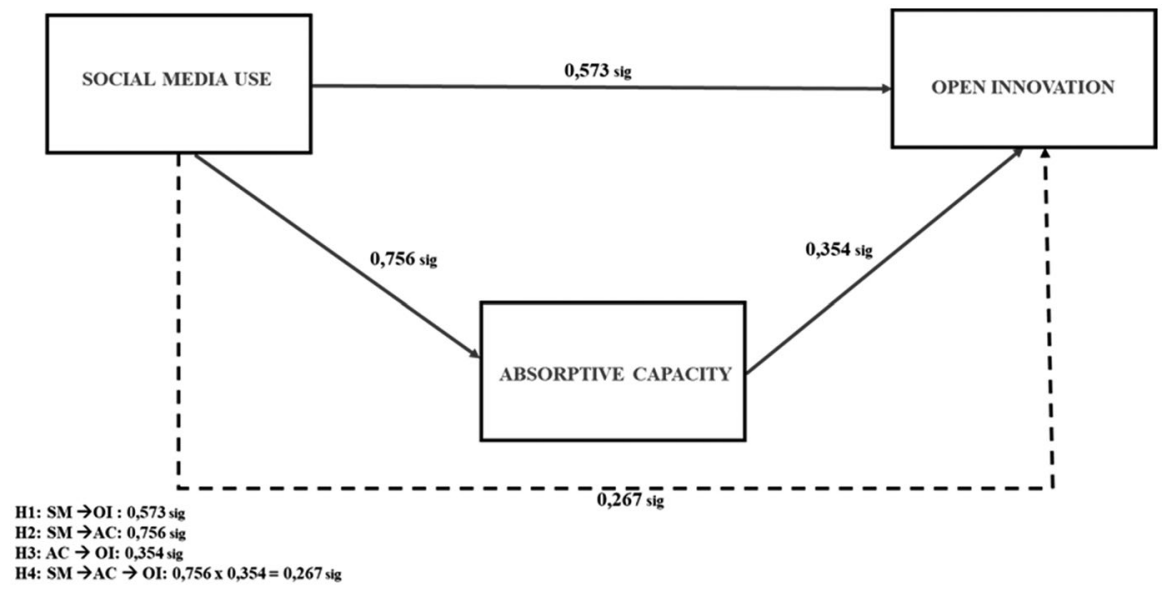

Fig. 2 Proposed research model 
The study has also researched the indirect effect, and it has proposed hypothesis 4 (H4) as a mediating effect of the absorptive capacity in the link between social media and open innovation. As Fig. 2 and Table 5 show, the indirect effect of the social media on open innovation, via absorptive capacity, is significant. In the research model, both the direct (0.573) and indirect (0.267) effects of SM and OI are significant. This means that there exists a mediator effect, and $\mathrm{H} 4$ is supported. The type of mediation is partial, because both the indirect and direct effects are significant (Cepeda-Carrion et al., 2017; Nitzl et al., 2016). In addition, the partial mediation is the type complementary because the direct effect (0.573) and indirect effect (0.267) point in the same (positive) direction. It indicates that a portion of the effect of SM on OI is mediated through absorptive capacity, while social media use still explains a portion of open innovation that is independent of the absorptive capacity (Cepeda-Carrion et al., 2017; Nitzl et al., 2016).

\section{Discussion}

This study employed a quantitative approach which enables understanding better the specific impact of social media use on open innovation, exploring the mediating mechanism of absorptive capacity in this relationship. Since social media is not only the result of real-time news and using press releases, it may also be the result of using unproven rumours, colloquial expressions or sayings (CegarraSánchez et al., 2018; Thompson, 2008); the result from this research provided an opportunity to reflect on Gruner and Power (2018)'s findings of social media activity. They found out that in some cases, social media activity negatively affects a firm's marketing activity. One possible explanation this study offers for these findings is the fact that despite social media is helpful for establishing twoway communication between communities and organizations (Ngai et al., 2015; Stankovic-Rice, 2012), it is no less true that it can also manipulate information and generate misinformation (Sánchez-Casado et al., 2015).

Table 5 Construct effects on endogenous variables (incl. lower and upper limits of 95\% confidence interval)

\begin{tabular}{|c|c|c|c|c|c|}
\hline \multirow{2}{*}{$\begin{array}{l}\text { Effects on } \\
\text { endogenous } \\
\text { variables }\end{array}$} & \multirow[t]{2}{*}{ Path coefficient } & \multicolumn{2}{|c|}{$\begin{array}{l}\text { Confidence } \\
\text { intervals }(95 \%)\end{array}$} & \multirow[t]{2}{*}{ Significance of effect ( $p$-value) } & \multirow{2}{*}{$\begin{array}{l}R^{2} \text { of } \\
\text { dependent } \\
\text { construct }\end{array}$} \\
\hline & & $5 \%$ CIlo & 95\%CIhi & & \\
\hline $\mathrm{SM} \rightarrow \mathrm{OI}(\mathrm{H} 1)$ & 0.573 & 0.409 & 0.806 & Yes $(0.001)$ & 0.759 \\
\hline $\mathrm{SM} \rightarrow \mathrm{AC}(\mathrm{H} 2)$ & 0.756 & 0.693 & 0.852 & Yes $(0.000)$ & 0.572 \\
\hline $\mathrm{AC} \rightarrow \mathrm{OI}(\mathrm{H} 3)$ & 0.354 & 0.099 & 0.527 & Yes $(0.000)$ & \\
\hline $\begin{array}{l}\mathrm{SM} \rightarrow \mathrm{AC} \rightarrow \mathrm{OI} \\
\quad(\mathrm{H} 4)\end{array}$ & 0.267 & -0.081 & 0.404 & $\begin{array}{l}\text { complementary partial } \\
\text { mediation }\end{array}$ & \\
\hline
\end{tabular}

$S M$ social media use, $O I$ open innovation practices, $A C$ absorptive capacity 
The findings of this study contribute to the current literature on social media, intended to be considered both together and separately in two important ways. First, the findings of this study contribute to expand what is known about the relationship between the use of social media and absorptive capacity. Results suggest that the use of social media is exogenous to absorptive capability. Second, results provide support for the theoretical proposition on the importance of absorptive capacity for contrasting and filtering external information (e.g. Costa \& Monteiro, 2016; Nätti et al., 2014; Zahra \& George, 2002). Therefore, and considering that the relationship between the use of social media and open innovation remains unclear (Torres de Oliveira et al., 2019), our findings shed lights on the topic, in the specific context of family firms. In this vein, while not all the external information provided by the social media needs to be channelled (hypothesis 1), a portion of the external information received from social media needs to be filtered and adapted to the company context (hypotheses 2 and 3).

Moreover, this investigation also contribute to family firms literature, and it is consistent with the prior literature in family firms (Chaudhary \& Batra, 2018) and has revealed that to reach sustainable competitive advantages, family businesses need to adequately combine and reconfigure their existing base of knowledge with new knowledge through interaction with the outside of firm, such as with social media users.

Regarding the first hypothesis, the results support that the higher the use of social media is, the more likely to benefit from the opening of new innovations. These results confirm the importance of social media for acquiring external information, which in turn can help companies gain more innovative opportunities in the family business. As Nambisan et al. (2017) highlighted, those digital platforms allow different collectives to openly collaborate, fostering knowledge sharing and crowdsourcing among them. This is fundamentally changing the way family firms innovate, shaping the scope and direction of the innovation processes. These findings are consistent with prior literature that suggest a facilitating role of social media tools on innovation (De Zubielqui et al., 2019; Mount \& Garcia, 2014; Pérez-González et al., 2017).

The second hypothesis concerning the relationship between the use of social media and absorptive capacity was also confirmed. Findings show that the higher the use of social media, the more likely a company is to absorb external knowledge. Thus, the use of social media tools is going to support organizational learning abilities of the family firms to acquire, assimilate, transform and exploit external knowledge into the firms' operations (Schlagwein \& Hu, 2017). Consistent with Ooms et al., (2015a, b), results suggest that social media can be considered boundary-spanning tools, which enable multi-directional interactions and are going to play a key role on building absorptive capacity. In other words, the closer the company is to the network with social media communities, the more opportunities it has to access diverse information to initiate knowledge exchange with other stakeholders and innovators (Ooms et al., 2015a, b).

Regarding the third hypothesis, results demonstrate how absorptive capacity appears as a key antecedent of open innovation practices. Thus, results support prior studies in the area which indicated that absorptive capacity is a key antecedent 
of innovation activities (García-Morales et al., 2007; Cepeda-Carrión et al., 2012; Leal-Rodríguez et al., 2014). Therefore, results confirm that to make full use of the external information captured via social media, family firms need to have established appropriate organizational processes and routines to transform this external information into knowledge that reflects more effective products and services. This finding emphasized the role of absorptive capacity as an important condition to transforming external information into real innovations, highlighting also the relevance of knowledge application and transformation in this process (Moilanen et al., 2014).

The results support the hypothesis that absorptive capacity also mediates the impact of social media use on open innovation (hypothesis 4). A possible explanation for these findings may relate to the fact that only a part of the external media information is valuable in itself (Thompson, 2008); another part needs to be filtered, updated and adapted in order to respond to current company needs (Sánchez-Casado et al., 2015). For example, absorptive capacity may allow family business to capture the right knowledge behind spam and fake news (Cegarra-Navarro et al., 2014), which in turn can lead to make effective decisions on how to innovate (Martinez et al., 2014). We think this is an important contribution because were managers to innovate and seize opportunities, they could not be sure that the use of social media is enough to satisfy new society demands. In fact, they should consider that the use of social media may be most usefully considered in combination with absorptive capacity.

The characteristics of family firms such as family members' unwillingness to lose control (e.g. Gómez-Mejía et al., 2007), the resource constraints shaped by their governance structures and size (e.g. Carney, 2005), the distinctive aspects of their social capital (e.g. Arregle et al., 2007) and long-term orientation (Miller \& Le BretonMiller, 2005) contribute to the collaborative innovation offered by social media can be a highly effective means of overcoming barriers to innovation and an important source of competitive advantage for innovation in family firms (De Mattos et al., 2013; Feranita et al., 2017; Hitt et al., 2000; Sirmon et al., 2008).

Thus, the results of the study offer relevant implications for managers in the family firms, showing the pathway they need to follow to leverage social media use to become more innovative and therefore more likely to reach competitive advantage and improve the performance. Results suggest that family firms should strategically use these tools to connect with different stakeholders to become more open to the environment, more responsive and capture also valuable ideas to develop new products and services which meet customers' requirements.

In addition, absorptive capacity appears as essential and necessary in order to make external knowledge available in a timely and complete manner. Consequently, to take advantage of all the potential that social media use can bring in this area, family firms need to develop specific organizational routines and an appropriate culture to foster absorptive capacity. Our paper suggests that managers should foster an appropriate culture of learning in their firms and provide specific training to develop the staff ability to acquire, integrate and use information captured in digital platforms. Additionally, in order to leverage the potential of this information, it is necessary to establish adequate communication processes and systems, to share this information across the firm and to use it to improve customer experience and generate 
new service ideas. Due to the fact that family businesses seek continuity in their business and tend to have a long-term orientation, knowledge management across generations becomes a requirement for family businesses (Chaudhary \& Batra, 2018; Moss et al., 2014) for the innovation and improve the performance.

\section{Conclusions, Limitations, and Future Research}

Based on the above discussion, the paper offers two valuable contributions to the literature.

First, this research provides empirical evidence of the real impact of social media use in enhancing open innovation practices. Results demonstrate that these tools offer a valuable communication channel to connect with key stakeholders, like customers, supplier or business partners and collaborate with them to develop new products and services. In current turbulent markets, with the current COVID-19 pandemic crisis, the capacity to innovate help family firms to quickly respond to market changes, so it has become a key driver of competitiveness. For example, the case of companies in the hospitality sector and how they must be able to do things differently and innovate in their business models, operations, products and services (delivery services) so that they can continue to stay in the market and achieve sustainable competitive advantages. Considering that empirical research on the specific impact on social media use on innovativeness remains scarce, particularly in a service context in family firms, the findings of this study complement the existing literature and provide a basis for future studies. According to our results, social media tools appear as a basic enabler of open innovation, as it allows family firms to create and capture valuable knowledge involving different stakeholders in the innovation process.

Second, findings confirm the key role played by absorptive capacity in this process. Results empirically demonstrate that to fully benefit from external knowledge captured via social media, family firms need to possess specific organizational processes to acquire and assimilate external knowledge and to have implemented specific routines to exploit this knowledge and transform it into new service ideas. Consequently, absorptive capacity emerges as a necessary condition to leverage external knowledge captured via social media to enhance open innovation activities.

At the level of business implications, we find 4 implications.

The first business implication is that by developing a measurement tool to quantify the SM of Spanish family firms, this study addresses an important empirical challenge for family firms, which is the contribution of social networks to non-financial returns, such as open innovation and absorptive capacity (Chukwujioke Agbimi, 2019).

The second is the use of the absorptive capacity variable, which as we know is part of knowledge management and is very good for family businesses because it will allow them to filter and contrast the information coming from social networks, which will provide them with higher quality information for their usual decision-making. 
Thirdly, it is clear that another business implication is that the company must significantly enhance the combination of its knowledge with the knowledge it can obtain from outside through its networks, in order to achieve sustainable competitive advantages. In relation to the above, the reconfiguration of existing knowledge in the family business would give more possibilities to achieve new innovations, as noted above.

Finally, in line with the above, companies at the managerial and strategic level must establish procedures and structures at the organizational level that transform all the above elements into external information that will enable them to make better decisions that will lead them to achieve all their business objectives.

We acknowledge that this study presents some limitations, which could be addressed in future research. First, the analysis was based on cross-sectional data. As social media use and innovation are dynamic phenomenon in nature, a longitudinal analysis would be helpful to enrich the findings. Second, a key-informant method was used, and we draw on the managers' perception for data collection. Although this method has been widely used and has its advantages, it also suffers from the limitation that could reflect the limited opinion of one person (Perez-Gonzalez et al., 2017). Future studies can include the vision of multiple respondents, to reinforce the obtained results. Finally, the sample examined was composed exclusively by Spanish family firms in the service sector. Additional studies are needed, including international samples, to validate and extrapolate the results in different contexts. In addition, future lines of research emanate from the study by proposing absorptive capacity as a mediator between SM and open innovation in family firms. The model proposed in the paper offers future researchers a field of study of family firms, a wide range of research avenues to discover the black box of SM in family firms (Strike et al., 2018). We could use other variables, such as value co-creation, to enhance the development of open innovation or the use of the market orientation variable to collect ideas that can improve the relationship of family firms with their market.

\section{Declarations}

Conflict of Interest The authors declare no competing interests.

\section{References}

Aguirre-Urreta, M. I., \& Rönkkö, M. (2018). Statistical inference with PLSc using bootstrap confidence intervals, MIS Quarterly, 42(3), 1001-1020. https://doi.org/10.25300/MISQ/2018/13587

Ali, M., \& Park, K. (2016). The mediating role of an innovative culture in the relationship between absorptive capacity and technical and non-technical innovation. Journal of Business Research, 69(5), 1669-1675.

Anderson, R. C., \& Reeb, D. M. (2003). Founding-family ownership and firm performance: Evidence from the S\&P 500. The Journal of Finance, 58(3), 1301-1328.

Aral, S., Dellarocas, C., \& Godes, D. (2013). Introduction to the special issue-social media and business transformation: A framework for research. Information Systems Research, 24(1), 3-13.

Arregle, J. L., Hitt, M. A., Sirmon, D. G., \& Very, P. (2007). The development of organizational social capital: Attributes of family firms. Journal of Management Studies, 44(1), 73-95. 
Baron, M. (2021). Open innovation capacity of the polish universities. Journal of the Knowledge Economy, 12(1), 73-95.

Barroso Martínez, A., Sanguino Galván, R., \& Bañegil Palacios, T. (2013). Study of factors influencing knowledge transfer in family firms. Intangible Capital, 9(4), 1216-1238.

Basco, R. (2010). Tipo de orientación familiar y prácticas de dirección y gobierno. Un estudio aplicado a las empresas familiares españolas. Revista Europea de Dirección y Economía de la Empresa, 19(2): 129-144.

Bhimani, H., Mention, A.-L., \& Barlatier, P. J. (2019). Social media and innovation: A systematic literature review and future research directions. Technological Forecasting and Social Change, 144, 251-269.

Block, J. (2009). Long-term orientation of family firms: an investigation of R\&D investments, downsizing practices, and executive pay. Springer Science \& Business Media.

Bollen, K. A. (1989). Structural equations with latent variables. John Wiley.

Brumana, M., Minola, T., Garrett, R. P., \& Digan, S. P. (2017). How do family firms launch new businesses? A developmental perspective on internal corporate venturing in family business. Journal of Small Business Management, 55(4), 594-613.

Carney, M. (2005). Corporate governance and competitive advantage in family-controlled firms. Entrepreneurship Theory and Practice, 29(3), 249-265.

Casprini, E., De Massis, A., Minin, A. D., Frattini, F., \& Piccaluga, A. (2017). How family firms execute open innovation strategies: The loccioni case. Journal of Knowledge Management, 21(6), 1459-1485.

Cegarra-Navarro, J. G., Eldridge, S., \& Wensley, A. K. P. (2014). Counter-knowledge and realised absorptive capacity. European Management Journal, 32(2), 165-176.

Cegarra-Navarro, J. G., \& Wensley, A. K. P. (2009). Congenital learning in the Spanish telecommunication industry. Journal of Business Venturing, 24(6). https://doi.org/10.1016/j.jbusvent.2008.05.009

Cegarra-Sánchez, J., Bolisani, E., Cegarra-Navarro, J. G., \& Martínez Caro, E. (2018). Online learning communities and their effects on relational capital. VINE Journal of Information and Knowledge Management Systems. https://doi.org/10.1108/VJIKMS-01-2018-0004

Cepeda-Carrión, G., Cegarra-Navarro, J. G., \& Jimenez-Jimenez, D. (2012). The effect of absorptive capacity on innovativeness: Context and information systems capability as catalysts. British Journal of Management, 23, 110-129.

Cepeda-Carrion, G., Nitzl, C., \& Roldán, J. L. (2017). Mediation analyses in partial least squares structural equation modeling: Guidelines and empirical examples (pp. 173-195). Springer.

Chaudhary, S., \& Batra, S. (2018). Absorptive capacity and small family firm performance: Exploring the mediation processes. Journal of Knowledge Management., 22(6), 1201-1216.

Chin, W. W. (1998). The partial least squares approach to structural equation modelling. Modern Methods for Business Research, 295(2), 295-336.

Chua, A. Y. K., \& Banerjee, S. (2013). Customer knowledge management via social media: The case of Starbucks. Journal of Knowledge Management, 17(2), 237-249.

Chukwujioke Agbimi, K. (2019). Social networking and the family business performance: A conceptual consideration. Journal of Entrepreneurship, Management and Innovation, 15(1), 83-122. https:// doi.org/10.7341/20191514

Chun-Yao, T. (2011). Knowledge absorptive capacity and innovation performance in KIBS. Journal of Knowledge Management, 15(6), 971-983.

Cohen, J. (1988). Statistical power analysis for the behavioral sciences (2nd ed.). Lawrence Erlbaum Associates Publishers.

Cohen, W. M., \& Levinthal, D. A. (1990). Absorptive capacity: A new perspective on learning and innovation. Administrative Science Quarterly, 35, 128-152.

Cohen, W. M., \& Levinthal, D. A. (2006). Absorptive capacity: A new perspective on learning and innovation. Administrative Science Quarterly. https://doi.org/10.2307/2393553

Costa, V., \& Monteiro, S. (2016). Key knowledge management processes for innovation: a systematic literature review. VINE Journal of Information and Knowledge Management Systems.

De Massis, A., Frattini, F., \& Lichtenthaler, U. (2013). Research on technological innovation in family firms: Present debates and future directions. Family Business Review, 26(1), 10-31.

De Mattos, C., Burgess, T. F., \& Shaw, N. E. (2013). The impact of R\&D-specific factors on the attractiveness of small-and medium-sized enterprises as partners vis-à-vis alliance formation in large emerging economies. $R \& D$ Management, 43(1), 1-20.

De Zubielqui, G. C., Fryges, H., \& Jones, J. (2019). Social media, open innovation \& HRM: Implications for performance. Technological Forecasting and Social Change, 144, 334-347. 
Escribano, A., Fosfuri, A., \& Tribó, J. A. (2009). Managing external knowledge flows: The moderating role of absorptive capacity. Research Policy. https://doi.org/10.1016/j.respol.2008.10.022

Feranita, F., Kotlar, J., \& De Massis, A. (2017). Collaborative innovation in family firms: Past research, current debates and agenda for future research. Journal of Family Business Strategy, 8(3), 137-156.

Fornell, C., \& Larcker, D. F. (1981). Evaluating structural equation models with unobservable variables and measurement error. Journal of Marketing Research, 18(1), 39-50.

Gallaugher, J., \& Ransbotham, S. (2010). Social media and customer dialog management at Starbucks. MIS Quarterly Executive, 9(4), 197-212.

Garcia-Morales, V. J., Martín-Rojas, R., \& Lardón-López, M. E. (2018). Influence of social media technologies on organizational performance through knowledge and innovation. Baltic Journal of Management, 13(3), 345-367.

García-Morales, V. J., Ruiz-Moreno, A., \& Llorens-Montes, F. J. (2007). Effects of technology absorptive capacity and technology proactivity on organizational learning, innovation and performance: An empirical examination. Technology Analysis \& Strategic Management, 19(4), 527-558.

Gómez-Mejía, L. R., Haynes, K. T., Núñez-Nickel, M., Jacobson, K. J. L., \& Moyano-Fuentes, J. (2007). Socioemotional wealth and business risks in family-controlled firms: Evidence from Spanish olive oil mills. Administrative Science Quarterly, 52(1), 106-137.

Gruner, R. L., \& Power, D. (2018). To integrate or not to integrate? Understanding B2B social media communications. Online Information Review.

Hair J, J. F., Hult, G. T. M., Ringle, C., \& Sarstedt, M. (2016). A pimer on partial least squares structural equation modeling (PLS-SEM).2nd edition, Sage Publications

Hair, J. F., Hult, G. T., Ringle, C. M., Sarstedt, M., Castillo-Apraiz, J., Cepeda Carrion, G., \& Roldán, J. L. (2019). Manual de Partial Least Squares Structural Equation Modeling (PLS-SEM), Omnia Science.

Hair Jr, J. F., Sarstedt, M., Hopkins, L., \& Kuppelwieser, V. G. (2014). Partial least squares structural equation modeling (PLS-SEM) An emerging tool in business research. European Business Review, 26(2), 106-121.

Henseler, J. (2017). Bridging design and behavioral research with variance-based structural equation modelling. Journal of Advertising, 46(1), 178-192.

Henseler, J., Ringle, C. M., \& Sarstedt, M. (2015). A new criterion for assessing discriminant validity in variance-based structural equation modelling. Journal of the Academy of Marketing Science, 43(1), $115-135$.

Henseler, J., Ringle, C. M., \& Sinkovics, R. R. (2009). The use of partial least squares path modeling in international marketing (pp. 277-319). Emerald Group Publishing Limited.

Hitt, M. A., Ireland, R. D., \& Lee, H. U. (2000). Technological learning, knowledge management, firm growth and performance: An introductory essay. Journal of Engineering and Technology Management, 17(3-4), 231-246.

Hoy, F., \& Sharma, P. (2010). Entrepreneurial family firms. Pearson College Division.

Huizingh, E. K. R. E. (2011). Open innovation: State of the art and future perspectives. Technovation, 31(1), 2-9.

Jalilvand, M. R., Vosta, L. N., Khalilakbar, R., Javad, K. P., \& Tabaeeian, R. A. (2019). The effects of internal marketing and entrepreneurial orientation on innovation in family businesses. Journal of the Knowledge Economy, 10(3), 1064-1079.

Jansen, J. J., Van Den Bosch, F. A., \& Volberda, H. W. (2005). Managing potential and realized absorptive capacity: How do organizational antecedents matter? Academy of Management Journal, 48(6), 999-1015.

Kaplan, A. M., \& Haenlein, M. (2010). Users of the world, unite! The Challenges and Opportunities of Social Media, Business Horizons, 53, 59-68.

Keegan, B. J., \& Rowley, J. (2017). Evaluation and decision making in social media marketing. Management Decision, 55(1), 15-31.

Lam, H. K., Yeung, A. C., \& Cheng, T. E. (2016). The impact of firms' social media initiatives on operational efficiency and innovativeness. Journal of Operations Management, 47-48, 28-43.

Lane, P. J., Koka, B. R., \& Pathak, S. (2006). The reification of absorptive capacity: A critical review and rejuvenation of the construct. Academy of Management Review, 31(4), 833-863.

Leal-Rodriguez, A. L., Roldan, J. L., Ariza-Montes, J. A., \& Leal-Millan, A. (2014). From potential absorptive capacity to innovation outcomes in project teams: The conditional mediating role of the realized absorptive capacity in a relational learning context. International Journal of Project Management, 32(6), 894-907. 
Martinez, M. G., Lazzarotti, V., Manzini, R., \& García, M. S. (2014). Open innovation strategies in the food and drink industry: Determinants and impact on innovation performance. International Journal of Technology Management. https://doi.org/10.1504/IJTM.2014.064588

Mention, A. L. (2011). Co-operation and co-opetition as open innovation practices in the service sector: Which influence on innovation novelty? Technovation, 31(1), 44-53.

Mention, A. L., Barlatier, P. J., \& Josserand, E. (2019). Using social media to leverage and develop dynamic capabilities for innovation. Technological Forecasting and Social Change, 144, 242-250.

Miller, D., \& Le Breton-Miller, I. (2005). Managing for the long run: lessons in competitive advantage from great family businesses. Harvard Business Press.

Moilanen, M., Østbye, S., \& Woll, K. (2014). Non-R\&D SMEs: External knowledge, absorptive capacity and product innovation. Small Business Economics, 43(2), 447-462.

Moss, T. W., Payne, G. T., \& Moore, C. B. (2014). Strategic consistency of exploration and exploitation in family businesses. Family Business Review, 27(1), 51-71.

Mount, M., \& Garcia, M. (2014). Social media: A tool for open innovation. California Management Review, 56(4), 124-143.

Nambisan, S., Lyytinen, K., Majchrzak, A., \& Song, M. (2017). Digital Innovation Management: Reinventing innovation management research in a digital world. MIS Quarterly, 41(1).

Naqshbandi, M. M., \& Tabche, I. (2018). The interplay of leadership, absorptive capacity, and organizational learning culture in open innovation: Testing a moderated mediation model. Technological Forecasting and Social Change, 133, 156-167.

Nätti, S., Pekkarinen, S., Hartikka, A., \& Holappa, T. (2014). The intermediator role in value co-creation within a triadic business service relationship. Industrial Marketing Management, 43(6), 977-984.

Ngai, E. W. T., Tao, S. S. C., \& Moon, K. K. L. (2015). Social media research: Theories, constructs, and conceptual frameworks. International Journal of Information Management. https://doi.org/10. 1016/j.ijinfomgt.2014.09.004

Nitzl, C., Roldan, J. L., \& Cepeda, G. (2016). Mediation analysis in partial least squares path modeling: Helping researchers discuss more sophisticated models. Industrial Management \& Data Systems, 116(9), 1849-1864.

Nunnally, J. C. (1978). Psychometric theory. McGraw-Hill Book Company.

Oltra, M. J., Flor, M. L., \& Alfaro, J. A. (2018). Open innovation and firm performance: The role of organizational mechanisms. Business Process Management Journal, 24(3), 814-836.

Ooms, W., Bell, J., \& Kok, R. A. (2015b). Use of social media in inbound open innovation: Building capabilities for absorptive capacity. Creativity and Innovation Management, 24(1), 136-150.

Ooms, W., Bell, J., \& Kok, R. A. W. (2015a). Use of social media in inbound open innovation: Building capabilities for absorptive capacity. Creativity and Innovation Management. https://doi.org/10. 1111/caim.12105

Palacios-Marqués, D., Merigó, J. M., \& Soto-Acosta, P. (2015). Online social networks as an enabler of innovation in organizations. Management Decision, 53(9), 1906-1920.

Papa, A., Santoro, G., Tirabeni, L., \& Monge, F. (2018). Social media as tool for facilitating knowledge creation and innovation in small and medium enterprises. Baltic Journal of Management, 13(3), 329-344.

Parveen, F., Jaafar, N. I., \& Ainin, S. (2016). Social media's impact on organizational performance and entrepreneurial orientation in organizations. Management Decision, 54(9), 2208-2234.

Patroni, J., Von Briel, F., \& Recker, J. (2021). Unpacking the social media-driven innovation capability: How consumer conversations turn into organizational innovations. Information \& Management, in Press, . https://doi.org/10.1016/j.im.2020.103267

Pérez-González, D., Trigueros-Preciado, S., \& Popa, S. (2017). Social media technologies' use for the competitive information and knowledge sharing, and its effects on industrial SMEs' innovation. Information Systems Management, 34(3), 291-301.

Pistrui, D., Huang, W., Oksoy, D., Jing, Z., \& Welsch, H. (2001). Entrepreneurship in China: Characteristics, attributes, and family forces shaping the emerging private sector. Family Business Review, 14(2), 141-152.

Popa, S., Soto-Acosta, P., \& Martinez-Conesa, I. (2017). Antecedents, moderators, and outcomes of innovation climate and open innovation: An empirical study in SMEs. Technological Forecasting and Social Change, 118, 134-142.

Qi, G., Hou, L., Chen, J., Liang, Y., \& Zhang, Q. (2021). How does user social network improve innovation outcomes on a virtual innovation platform?: Evidence from LEGO ideas platform. Journal of Global Information Management, 29(3), 188-211. 
Rangus, K., Drnovšek, M., Di Minin, A., \& Spithoven, A. (2017). The role of open innovation and absorptive capacity in innovation performance: Empirical evidence from Slovenia. Journal of East European Management Studies, 22(1), 39-62.

Rass, M., Dumbach, M., Danzinger, F., Bullinger, A. C., \& Moeslein, K. M. (2013). Open innovation and firm performance: The mediating role of social capital. Creativity and Innovation Management, 22, $177-194$.

Rigdon, E. E. (2016). Choosing PLS path modeling as analytical method in European management research: A realist perspective. European Management Journal, 34(6), 598-605.

Rigdon, E. E., Sarstedt, M., \& Ringle, C. M. (2017). On comparing results from CB-SEM and PLS-SEM: Five perspectives and five recommendations. Marketing Zfp, 39(3), 4-16.

Ringle, C. M., Wende, S., \& Becker, J. M. (2015). SmartPLS 3. Bönningstedt: SmartPLS. Retrieved July, 15, 2016, http://www.smartpls.com

Ruiz, M., Sessarego, A., \& Guzman-Sanza, R. (2010). A research about of family firm definition. Available at SSRN: http://ssrn.com/abstract=1551410 (Last access date; February 11th, 2010).

Sánchez-Casado, N., Cegarra-Navarro, J. G., \& Tomaseti-Solano, E. (2015). Linking social networks to utilitarian benefits through counter-knowledge. Online Information Review, 39(2), 179-196.

Sashi, C. M. (2012). Customer engagement, buyer-seller relationships, and social media. Management Decision, 50(2), 253-272.

Schlagwein, D., \& Hu, M. (2017). How and why organisations use social media: Five use types and their relation to absorptive capacity. Journal of Information Technology, 32(2), 194-209.

Scuotto, V., Giudice, D., \& M., Carayannis, E. (2017). The effect of social networking sites and absorptive capacity on firms' innovativeness. Journal of Technology Transfer, 42, 409-424.

Sharma, P., Chrisman, J. J., \& Gersick, K. E. (2012). 25 years of family business review: reflections on the past and perspectives for the future.

Sirmon, D. G., Arregle, J. L., Hitt, M. A., \& Webb, J. W. (2008). The role of family influence in firms' strategic responses to threat of imitation. Entrepreneurship Theory and Practice, 32(6), 979-998.

Sirmon, D. G., \& Hitt, M. A. (2003). Managing resources: Linking unique resources, management, and wealth creation in family firms. Entrepreneurship Theory and Practice, 27(4), 339-358.

Spithoven, A., Clarysse, B., \& Knockaert, M. (2010). Building absorptive capacity to organise inbound open innovation in traditional industries. Technovation, 30, 130-141.

Stankovic-Rice, B. L. (2012). Social media strategies to advance organizational change, Dissertation Abstracts International Section A: Humanities and Social Sciences.

Statista. (2021). Global social networks ranked by number of users 2021, available at: https://www.statista. com/statistics/272014/global-social-networks-ranked-by-number-of-users/ (accessed 24/09/2021).

Strike, V. M., Michel, A., \& Kammerlander, N. (2018). Unpacking the black box of family business advising: Insights from psychology. Family Business Review, 31(1), 80-124. https://doi.org/10. 1177/0894486517735169

Tajvidi, R., \& Karami, A. (2017). The effect of social media on firm performance, Computers in Human Behavior, 1-10.

Tajvidi, R., \& Karami, A. (2021). The effect of social media on firm performance. Computers in Human Behavior, 115. https://doi.org/10.1016/j.chb.2017.09.026

Thompson, D. (2008). Counter-knowledge. Atlantic Books.

Torres de Oliveira, R., Indulska, M., Steen, J., \& Verreynne, M. L. (2019). Towards a framework for innovation in retailing through social media. Journal of Retailing and Consumer Services. https:// doi.org/10.1016/j.jretconser.2019.01.017

West, J., Salter, A., Vanhaverbeke, W., \& Chesbrough, H. (2014). Open innovation: The next decade. Research Policy. https://doi.org/10.1016/j.respol.2014.03.001

Zahra, S., \& George, G. (2002). Absorptive capacity: A review, reconceptualisation, and extension. Academy of Management Review, 27, 185-203.

Publisher's Note Springer Nature remains neutral with regard to jurisdictional claims in published maps and institutional affiliations. 


\section{Authors and Affiliations}

Ignacio Cepeda-Carrion ${ }^{1}$ - Jaime Ortega-Gutierrez ${ }^{1} \cdot$ Aurora Garrido-Moreno $^{2}$. Juan-Gabriel Cegarra-Navarro ${ }^{3}$

Jaime Ortega-Gutierrez

joguti@us.es

Aurora Garrido-Moreno

agarridom@uma.es

Juan-Gabriel Cegarra-Navarro

juan.cegarra@upct.es

1 Faculty of Businesses and Economics Sciences, Department of Business Administration and Marketing, University of Seville, Av Ramón Y Cajal, 1, 41018 Seville, Spain

2 Faculty of Social Studies and Social Work, Department of Management, University of Malaga, Av. Francisco Trujillo Villanueva, 29001 Malaga, Spain

3 Faculty of Business Science, Business Administration Department, Polytechnic University of Cartagena, Calle Real, 3, 30201 Cartagena, Murcia, Spain 